\title{
Compound-specific radiocarbon analysis (CSRA) of SOA-related organic compounds in the atmosphere
}

\author{
GAN ZHANG" ${ }^{\wedge}$,BUQING XU',TIANGANG TANG',ZHINENG \\ CHeng', Jun Li', HAIRONG CHENG ${ }^{2}$, CHENGDE SHEN', \\ PING DING',AND SANYUAN ZHU'
}

State Key Laboratory of Organic Geochemistry, Guangzhou Institute of Geochemistry, Chinese Academy of Sciences, Guangzhou 510640, China (Corresponding author: zhanggan@gig.ac.cn)

${ }_{2}^{2}$ School of Resource and Environmental Sciences, Wuhan University, Wuhan, China

A better understanding of the fate of different organic species in the atmosphere is always needed. Radiocarbon (14C) analysis is a powerful tool in distinguishing fossil-fuel carbon sources from no-fossil/contemporary carbon sources. Together with stable carbon (13C ) and deuterium (D) isotopes, more information about the sources and atmospheric processes could be retrieved for targeted organic species either in the air particulates or as precursors of secondary organic aerosol (SOA). Based on the Accelerated Mass Spectrometer facility (GIG-CAMS) in Guangzhou Institute of Geochemistry, Chinese Academy of Sciences, methodologies were developed for measuring radiocarbon of different organic species in the atmosphere. In this presentation, we will firstly introduce new method development and application of compound-specific radiocarbon analysis (CSRA) of organic poly-acids, such as oxalic acid, in aerosols from a super-station in the Pearl River Delta of southern China. Then we will present results of CSRA of gaseous naphthalene and methyl-naphthalene(s), as surrogates of intermediately volatile organic compounds (IVOCs) which would make great contribution to SOA formation, together with compound-pecific isotope analysis of $13 \mathrm{C}$ and D of the naphthalenes in the atmosphere of 5 Chinese cities. 